\title{
Determinants of neonatal mortality in Nigeria: evidence from the 2008 demographic and health survey
}

Osita Kingsley Ezeh" ${ }^{1 *}$, Kingsley Emwinyore Agho ${ }^{1}$, Michael John Dibley ${ }^{2}$, John Hall ${ }^{3}$ and Andrew Nicholas Page ${ }^{1}$

\begin{abstract}
Background: Nigeria continues to have one of the highest rates of neonatal deaths in Africa. This study aimed to identify risk factors associated with neonatal death in Nigeria using the 2008 Nigeria Demographic and Health Survey (NDHS).

Methods: Neonatal deaths of all singleton live-born infants between 2003 and 2008 were extracted from the 2008 NDHS. The 2008 NDHS was a multi-stage cluster sample survey of 36,298 households. Of these households, survival information of 27,147 singleton live-borns was obtained, including 996 cases of neonatal mortality. The risk of death was adjusted for confounders relating to individual, household, and community level factors using Cox regression.

Results: Multivariable analyses indicated that a higher birth order of newborns with a short birth interval $\leq 2$ years (hazard ratio $[H R]=2.19$, confidence interval $[\mathrm{Cl}]: 1.68-2.84$ ) and newborns with a higher birth order with a longer birth interval $>2$ years ( $\mathrm{HR}=1.36, \mathrm{Cl}: 1.05-1.78)$ were significantly associated with neonatal mortality. Other significant factors that affected neonatal deaths included neonates born to mothers younger than 20 years ( $H R=4.07, \mathrm{Cl}: 2.83-5.86)$, neonates born to mothers residing in rural areas compared with urban residents $(H R=1.26, \mathrm{Cl}: 1.03-1.55)$, male neonates $(H R=1.30, \mathrm{Cl}: 1.12-1.53)$, mothers who perceived their neonate's body size to be smaller than the average size ( $H R=2.10, \mathrm{Cl}: 1.77-2.50)$, and mothers who delivered their neonates by caesarean section ( $\mathrm{HR}=2.80, \mathrm{Cl}: 1.84-4.25)$.

Conclusions: Our study suggests that the Nigerian government needs to invest more in the healthcare system to ensure quality care for women and newborns. Community-based intervention is also required and should focus on child spacing, childbearing at a younger age, and poverty eradication programs, particularly in rural areas, to reduce avoidable neonatal deaths in Nigeria.
\end{abstract}

Keywords: Determinants, Neonatal mortality, Cox regression, Nigeria

\section{Background}

Neonatal mortality is still a significant public health problem worldwide, and accounts for more than $60 \%$ of newborn deaths before their first birthday [1]. Of the world's 7.7 million deaths in those aged younger than 5 years, 3.1 million occurred after birth through to 1 month of life (neonatal deaths) [2]. Nearly $99 \%$ of these neonatal deaths occur in low- and middle-income countries, mostly in sub-Saharan Africa, including Nigeria [3]. The majority of

\footnotetext{
* Correspondence: ezehosita@yahoo.com

${ }^{1}$ School of Science and Health, University of Western Sydney, Locked Bag

1797, Penrith, New South Wales (NSW) 2571, Australia

Full list of author information is available at the end of the article
}

these deaths are caused by preventable or treatable diseases, such as infectious diseases, which contribute to approximately $36 \%$ of these deaths [3]. Previous studies have shown that the global decline in neonatal mortality rates has been slower compared with infant and under- 5 years of age mortality rates, especially in the sub-Sahara African region $[1,2,4]$.

Globally, Nigeria ranks second to India with the highest number of neonatal deaths, with the highest reported number in Africa [5]. Each year in Nigeria, more than a quarter million neonates die, which translates to approximately 700 neonates every day [5]. Neonatal mortality remains disturbingly high in Nigeria, despite the significant

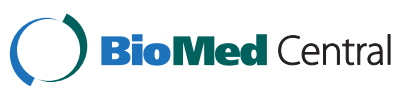


decline in most parts of the developing world, including some sub-Sahara African countries, such as Ghana and Uganda [6]. A recent United Nations (UN) report on childhood mortality reported that over the last 2 decades, the Nigerian neonatal mortality rate (NMR) dropped by only 20.4\%, from 49 deaths per 1000 live births in 1990 to 39 in 2011 [5]. Similarly, evidence from the Nigeria Demographic and Health Survey (NDHS) also indicated a marginal decline of $4.8 \%$ (42 deaths per 1000 live births in 1990 to 40 in 2008) [7]. The 39 and 40 neonatal deaths per 1000 live births reported by the UN and NDHS, respectively, can be interpreted as approximately one in every 25 neonates born in Nigeria died in the first month of life.

Previous studies on neonatal mortality in Nigeria have indicated that low birth weight, lack of antenatal care, maternal illness, mother's age, prematurity, and birth asphyxia are linked with neonatal mortality, but these studies were all hospital-based case-control and experimental studies [8-11]. Limitations of these hospitalbased case-control and experimental studies are that neonates delivered at home were not included and that control groups were not population based, and may not be generalizable to the wider Nigerian population. Evidence from the NDHS showed that home delivery in Nigeria remains high. An example of this situation is in the 1999 NDHS, where approximately $58 \%$ of neonates were delivered at home [12], and this number rose to $66 \%$ in the 2003 NDHS [13], and was $62 \%$ in the 2008 NDHS [7]. Importantly, neonatal mortality rates play an increasingly important role in childhood mortality, and there are currently no effective community based intervention programs in Nigeria specifically targeting neonatal mortality.

The main goal of this study was to determine factors associated with neonatal mortality using the 2008 NDHS. Findings from the study would be useful to public health researchers and policy makers in reviewing and designing new community based intervention strategies aimed at reducing neonatal mortality in Nigeria. Therefore, this study presents population-based data on risk factors associated with neonatal mortality in Nigeria.

\section{Methods}

This study was based on a public domain dataset that is freely available online. The data were collected for the NDHS 2008 [7]. The survey was conducted by the National Population Commission in conjunction with the ICF Macro, Calverton, MD, USA, in 36 states and the federal capital territory [7].

The 2008 NDHS was a stratified two-stage cluster design. Each state was stratified into two distinct groups of urban and rural areas. The census enumeration areas of the 2006 population census were used as the clusters for the 2008 NDHS. In the first stage, clusters were selected based on probability proportionate to the population size among its urban and rural areas. In each of the selected clusters, a complete listing of households was obtained. The listed households then served as the sampling frame for the selection of households to be interviewed in the second stage. Thereafter, a systematic sampling with equal probability was used in the second stage in selecting the specified number of households in each cluster for interview [7].

A structured questionnaire was used for interviewing the selected households for the 2008 NDHS. The questionnaires that were administered to the respondent household members were the household questionnaire, the women's questionnaire, and the men's questionnaire. These questionnaires consisted of a series of questions on population and health issues. The household questionnaire recorded all of the usual residents of the selected household and their characteristics, such as age, sex, education, and their relationship with the head of the household, as well as information on amenities and features of the household's dwelling unit. Additionally, the survey collected data on height and weight measurements for children aged younger than 5 years, and women aged 15-49 years. The women's questionnaire consists of information included, but not limited to, birth history, childhood mortality, fertility preferences, knowledge and use of family planning methods, antenatal care, delivery, postnatal care, vaccinations, and childhood illnesses, as well as malaria prevention and treatment. The 2008 NDHS men's questionnaire was the same as the women's questionnaire, but did not contain a detailed reproductive history, maternal and child health, or nutrition. However, notably, gestational age, intrapartum-related complications, and birth asphyxia, which could potentially improve neonatal data, were not collected in the 2008 NDHS.

A total of 888 clusters were selected for the 2008 NDHS sample survey. Of these clusters, a total of 36,298 households were selected for interview in the 2008 NDHS. At the time of the survey, nearly $5 \%$ of the households were not occupied. However, more than $98 \%$ of the occupied households were successfully interviewed. A total of 34,596 eligible women aged between 15 and 49 years were interviewed, yielding a response rate of $96.5 \%$. The analysis was restricted to all singleton live births for a 5 -year period preceding the 2008 NDHS to reduce recall bias about birth and death dates reported by mothers.

\section{Descriptive study variables}

A conceptual framework of child survival in developed and developing countries has been developed by other authors [14-17]. However, the model by Moseley [15] is 
regarded as the most elaborate and systematic conceptual framework [18], and is frequently referenced in other studies on childhood mortality [19]. As a result, our study used the Moseley [15] conceptual framework as the basis for identifying important risk factors for neonatal mortality in Nigeria.

The outcome variable for this study was neonatal death as reported by the mothers who participated in the survey, and it was defined as the death of a neonate between birth and 1 month of life. This takes a binary form, such that neonatal death will be regarded as a success $(1=$ if death occurs in the specified age period) or failure $(0=$ if the newborn is alive in the specified age period). The outcome variable was examined against all confounding variables, and these variables were classified into three distinct groups: community level factors, household factors, and individual level factors consisting of socioeconomic factors (Table 1). These variables were used in the study to identify risk factors associated with neonatal mortality. Based on the adapted conceptual framework, all of the confounding variables influencing neonatal mortality along with their categorisations are shown in Table 1.

There were two community level factors used, residence type and geopolitical zone, while the wealth index variable measured the economic status of the household. The wealth index variable was constructed using household facilities and assets, which were weighted, using a principal components analysis [20]. The range of assets considered were a television, radio, and fridge, and ownership of a car, bicycle, and motorcycle. Household facilities were also included, such as the source of drinking water, type of toilet, electricity, and type of building materials used in the place of dwelling. Among the individual factors, there were 14 variables of maternal and child characteristics (Table 1).

In this analysis, two perinatal healthcare variables, antenatal care and postnatal care, were not included because nearly one third of the information was missing. Additionally, we did not include birth weight of neonates because almost half of the neonates were not weighed at the time of birth. However, perceived newborn size at birth by mothers (small or very small, and average or large) was used instead of birth weight because a previous study showed that there is a close relationship between mean birth weight and perceived newborn size by the mother [21].

\section{Statistical analysis}

The NMR was calculated by using a similar method described by Rutstien and Rojas [22]. The crude hazard ratios (HRs) for factors associated with neonatal death were determined by univariate analyses, which were performed using a Cox proportional hazards regression model. In
Table 1 Definition and categorisation of potential variables used in identifying risk factors associated with neonatal mortality

POTENTIAL CATEGORISATION
VARIABLES

\section{Community level \\ factors}

Residence

Type of the residence $(1=$ urban; $2=$ rural $)$

Geopolitical zone

Zone $(1=$ North Central; $2=$ North East; $3=$ North

West; $4=$ South East; $5=$ South West; $6=$ South

South)

Household factor

Wealth index

Wealth ( 1 = Poor; 2 = Middle; 3 = Rich)

Individual level

factors

Maternal religion

Maternal religion ( $1=$ traditionalist or other;

2 = Islam; 3 = catholic or other Christian)

Maternal working

status

Maternal working status ( 1 = not working;

$2=$ working)

Maternal BMI

Maternal BMI (1 = BMI >18.5; $2=\mathrm{BMI} \leq 18.5)$

Maternal age at first $\quad$ Age at first birth $(1=<20 ; 2=20-29 ; 3=30-39$. child $4=40-49$ )

Maternal age

Mother's age $(1<20 ; 2=20-29 ; 3=30-39$; $4=40-49$ )

Maternal literacy level Literacy level $(1=$ Able to read parts of $\&$ whole sentence; 2 = Cannot read at all)

Paternal education Education status $(1=$ No education; 2 = Primary; $3=$ Secondary or higher)

Maternal education Education status ( 1 = No education; 2 = Primary; $3=$ Secondary or higher)

Sex

Sex of the neonate $(1=$ Female; 2 = Male)

Birth order and birth Birth order and birth interval of neonate interval

$(1=$ Second or third child, interval $>2$ years; $2=$ First child; $3=$ Second or third child, interval $\leq 2$ years; $4=$ Fourth or higher child, interval $>2$ years; $5=$ Fourth or higher child, interval $\leq 2$ years)

Birth place

Place of delivery of the neonate

( 1 = Home; 2 = Health facility)

Mother's perceived baby size

Maternal assessment of the neonate size at birth

Antenatal care ( 1 = Average or Larger; $2=$ Small or very small)

Mode of delivery

Antenatal care received by mother's $(1=$ Yes; 2 = No)

Delivery assistance Birth attendant during delivery $(1=$ Health

Mode of delivery $(1=$ non-caesarean; $2=$ caesarean section)

professional; 2 = non-Health professional)

Desire for pregnancy Mother's desire for baby ( 1 = Wanted then; $2=$ Wanted later; 3 = Wanted no more)

Postnatal care

Postnatal care of mother's after birth $(1=$ Yes; $2=$ No)

addition, multivariable analysis was used to examine the association between the potential independent variables and the study outcome. Analyses were performed using STATA/MP version 12.0 (StataCorp, College Station, TX, 
Table 2 Neonatal mortality rates (NMR) with 95\% confidence interval $(\mathrm{Cl})$

\begin{tabular}{lccc}
\hline Covariates & $\begin{array}{c}\text { Total live } \\
\text { births }\end{array}$ & $\begin{array}{c}\text { Neonatal } \\
\text { deaths }\end{array}$ & $\begin{array}{c}\text { NMR } \\
{[95 \% \mathrm{Cl}]}\end{array}$ \\
\hline Community level factors & & &
\end{tabular}

Community level factors

Residence type

Rural

8070

253

$31.3(29.2-33.4)$

Geopolitical zone

North Central

North East

North West

South East

South West

South South

Household

wealth index

Poor

Middle

Rich

Individual related factors

Mother's religion

Traditionalist and other

Islam

Catholic and other

Christian

Missing

Mother's age

at first birth

Less than 20 years

20 - 29 years

30 - 49 years*

Mother's age

$<20$

20-29

30-39

40-49

Mother's

literacy level

Cannot read at all

Able to read

Mother's

education

No education

Primary

Secondary or higher
19077

3693

4452

8529

2611

3516

4345

12542

10013

4592

464

15018

11517

148

15391

10634

12685

6255

743

$38.9(36.6-41.3)$

$32.6(30.6-34.9)$

$39.6(37.2-42.0)$

35.7 (33.5- 37.9)

$41.5(39.1-43.9)$

30.4 (28.3- 32.5)

$$
132
$$

$39.3(36.9-41.7)$

35.6 (33.4- 37.8)

$31.6(29.5-33.5)$

142

Male

Mother's perceived baby size

Small or very small

Average or larger

Missing

Birth order and

birth interval

First child

5331

37.6 (35.3- 39.9)

15755

10702

690

1471

13096

9797

2783

$$
598
$$

363

35

34.2 (32.0- 36.4)

52.8 (50.1- 55.3)

\section{2}

$65.0(62.0-68.0)$

451

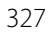

126

8207

448

3062

577

9389

17121

64

2 or 3 child,

interval $>2$

2 or 3 child,

interval $\leq 2$

4 or more child,

interval $>2$

4 or more child, interval $\leq 2$

3743

22778

626

$34.5(32.3-36.7)$

33.1 (30.9- 35.3)

Mode of delivery

$44.7(42.2-47.2)$

Non-caesarean

Caesarean section

Missing

6444

2652

9369

3352

Baby weight

at birth

Less than

2500 grammes

349

2500 - 3500 grammes

3110

1458

Greater than

3500 grammes

$34.6(32.4-36.8)$
43.4 (40.9- 45.9)

Table 2 Neonatal mortality rates (NMR) with $95 \%$ confidence interval (CI) (Continued)

Wanted then

23880

1669

1150

23508

868

37.0 (34.7- 39.3)

110

$35.0(32.8-37.2)$

18

332

638

35.8 (33.5- 38.0)

13342

13806

424

572

31.7 (29.6- 33.8)

210

$57.0(54.2-59.8)$

685

$30.0(27.9-32.1)$

102

249

47.6 (45.0- 50.2)

160

$24.3(22.5-26.2)$

135

$50.2(47.5-52.9)$

258

$27.3(25.3-29.3)$

194

$57.6(54.7-60.5)$

16

45

15

$9.2(8.1-10.3)$

Not weighed

18923

767
$46.6(44.0-49.2)$

14.7 (13.3- 16.1)

$40.7(38.3-43.1)$

35.8 (33.5- 38.1)

89.9 (86.3- 93.5)

5

53 
Table 2 Neonatal mortality rates (NMR) with $95 \%$ confidence interval (CI) (Continued)

\begin{tabular}{lccc}
\hline $\begin{array}{l}\text { Delivery assistance } \\
\text { Health professional }\end{array}$ & 10331 & 381 & $37.0(34.7-39.3)$ \\
$\begin{array}{l}\text { non-Health } \\
\text { professional }\end{array}$ & 16440 & 555 & 33.8 (31.6- 36.0) \\
$\begin{array}{l}\text { Missing } \\
\text { Postnatal check-up }\end{array}$ & 377 & 61 & \\
O - 2 days & 4372 & 112 & 26.1 (24.2- 28.0) \\
3 - 41 days & 3001 & 78 & $26.0(24.1-27.9)$ \\
$\begin{array}{l}\text { Don't know/missing } \\
\text { Birth place of child }\end{array}$ & 19774 & 806 & \\
Health facility & 9917 & 361 & $36.8(34.5-39.1)$ \\
Home & 16962 & 579 & 34.1 (31.9- 36.3) \\
Missing & 268 & 56 & \\
Antenatal care & & & \\
Yes & 9421 & 232 & $24.6(22.7-26.5)$ \\
No & 6316 & 169 & 26.5 (24.6- 28.4) \\
Missing & 11411 & 595 &
\end{tabular}

*Interval for 30-39 years and 40-49 years were merged.

NMR not calculated for missing values.

USA). Cox proportional hazards models were fitted using STATA survey commands to adjust for the cluster sampling design, weights, and the calculation of standard errors.

The multivariable analysis models conducted used a stepwise backwards elimination procedure to identify independent variables that were significantly associated with the study outcome. To avoid any statistical bias, we double checked our backward elimination method by using the following procedures: (1) we entered only potential risk factors with a $\mathrm{p}$ value $<0.20$ obtained in the univariable analysis for backward elimination process, (2) we tested the backward elimination by including all of the variables (all potential risk factors), and (3) we tested and reported any collinearity in the final model. HRs and 95\% confidence intervals (CIs) were calculated to assess the adjusted risk factors that affect study outcome, and those with $\mathrm{p}<0.05$ were retained in the final model.

\section{Results}

Table 2 shows the number of live births, the number of neonatal deaths and NMR by community, the household wealth index, and individual level factors. A weighted total of 27,147 singleton live births of children aged younger than 5 years occurred within the 5 -year period preceding the 2008 NDHS, of which the total neonatal deaths over this period was 996 (Table 2). Neonates born to mothers residing in rural residences had a higher NMR than those living in urban residences (NMR: 38.9 vs 31.3). The NMR for neonates born to mothers in poor households was higher than that in mothers in middleclass households (NMR: 39.3 vs 35.6). Neonates whose mothers perceived them as small or a smaller size, had a greater NMR than those of average or larger size (NMR: 57.0 vs 30.0). The majority of live-born neonates were not weighed at birth, and more than half of the neonatal deaths occurred at home.

Neonates delivered by caesarean section had a higher NMR than those born vaginally (NMR: 89.9 vs 35.8 ). The NMR for male neonates was higher than that for female neonates (NMR: 41.4 vs 31.7).

\section{Multivariable analysis}

Newborns born to mothers residing in rural areas had a higher risk of neonatal mortality than those who lived in urban areas $(\mathrm{HR}=1.26,95 \% \mathrm{CI}$ : $1.03-1.55, \mathrm{p}=0.026)$. Compared with neonates born to mothers aged between 30 and 39 years, neonates born to younger mothers ( $<20$ years) $(\mathrm{HR}=4.07,95 \% \mathrm{CI}: 2.83-5.86, \mathrm{p}<0.001)$ reported a significantly higher risk of neonatal deaths. When the place of residence was replaced by household wealth index in the final model, neonates born to mothers in poor households had a high risk of neonatal death, although this was not statistically significant $(\mathrm{HR}=1.24,95 \% \mathrm{CI}: 0.93-1.65)$.

Male neonates were more likely $(\mathrm{HR}=1.30,95 \% \mathrm{CI}$ : $1.12-1.53, p=0.001)$ to die than female neonates in the first month of life. Neonates delivered by caesarean section had a significantly higher risk of neonatal mortality $(\mathrm{HR}=2.80,95 \% \mathrm{CI}: 1.84-4.25, \mathrm{p}<0.001)$ compared with non-caesarean delivery. Neonates whose birth size were perceived by their mothers as small or smaller were also more likely to die than those of average or larger-sized neonates $(\mathrm{HR}=2.10,95 \% \mathrm{CI}: 1.77-2.50, \mathrm{p}<0.001)$.

As shown in Table 3, there was a significantly higher risk of neonatal death for fourth or higher birth order neonates with a short birth interval $\leq 2$ years $(\mathrm{HR}=2.19$, 95\% CI: 1.68-2.84, $\mathrm{p}<0.001$ ), second or third birth order neonates with a short birth interval $\leq 2$ years $(\mathrm{HR}=1.75$, 95\% CI: $1.31-2.34, \mathrm{p}<0.001)$, and fourth or higher birth order with a longer birth interval $>2$ years $(\mathrm{HR}=$ 1.36, 95\% CI: $1.05-1.78, \mathrm{p}=0.022$ ) compared with second or third birth order neonates with a longer birth interval $>2$ years.

\section{Discussion}

The overall aim of this study was to identify risk factors associated with neonatal mortality in Nigeria using a nationally representative sample. This study showed several factors that were significantly associated with neonatal mortality after adjusting for confounding factors, and each of these factors are discussed below. 
Table 3 Adjusted and unadjusted hazard ratios ( $95 \%$ confidence interval $[\mathrm{Cl}]$ ) for variables associated with neonatal mortality

\begin{tabular}{|c|c|c|c|c|c|c|}
\hline \multirow[t]{2}{*}{ Variables } & \multicolumn{3}{|c|}{ Unadjusted } & \multicolumn{3}{|c|}{ Adjusted $^{\wedge}$} \\
\hline & HR & {$[95 \% \mathrm{Cl}]$} & $P$ & $\overline{H R}$ & {$[95 \% \mathrm{Cl}]$} & $P$ \\
\hline \multicolumn{7}{|l|}{ Community level factors } \\
\hline \multicolumn{7}{|l|}{ Residence type } \\
\hline Urban & 1.00 & & & 1.00 & & \\
\hline Rural & 1.36 & $(1.11-1.66)$ & 0.003 & 1.26 & $(1.03-1.55)$ & 0.026 \\
\hline \multicolumn{7}{|l|}{ Geopolitical zone } \\
\hline North Central & 1.00 & & & & & \\
\hline North East & 1.23 & $(0.98-1.55)$ & 0.072 & & & \\
\hline North West & 1.07 & $(0.85-1.37)$ & 0.540 & & & \\
\hline South East & 1.12 & $(0.79-1.59)$ & 0.536 & & & \\
\hline South West & 1.28 & $(0.97-1.68)$ & 0.079 & & & \\
\hline South South & 0.82 & $(0.59-1.14)$ & 0.235 & & & \\
\hline \multicolumn{7}{|l|}{ Household wealth index } \\
\hline Poor & 1.45 & $(1.11-1.89)$ & 0.006 & & & \\
\hline Middle & 1.20 & $(0.91-1.59)$ & 0.189 & & & \\
\hline Rich & 1.00 & & & & & \\
\hline \multicolumn{7}{|l|}{ Individual related factors } \\
\hline \multicolumn{7}{|l|}{ Mother's religion } \\
\hline Traditionalist and other & 1.00 & & & & & \\
\hline Islam & 0.80 & $(0.48-1.31)$ & 0.370 & & & \\
\hline Catholic and other Christian & 0.88 & $(0.53-1.45)$ & 0.605 & & & \\
\hline \multicolumn{7}{|l|}{ Mother's age at first birth } \\
\hline Less than 20 years & 1.00 & & & & & \\
\hline 20 - 29 years & 0.88 & $(0.75-1.04)$ & 0.127 & & & \\
\hline $30-49$ years* & 1.34 & $(0.85-2.13)$ & 0.209 & & & \\
\hline \multicolumn{7}{|l|}{ Mother's age } \\
\hline$<20$ & 4.02 & $(2.99-5.40)$ & $<0.001$ & 4.07 & $(2.83-5.86)$ & $<0.001$ \\
\hline $20-29$ & 1.12 & $(0.93-1.33)$ & 0.226 & 1.22 & $(1.00-1.49)$ & 0.056 \\
\hline 30-39 & 1.00 & & & 1.00 & & \\
\hline $40-49$ & 1.34 & $(1.04-1.71)$ & 0.023 & 1.27 & $(0.99-1.63)$ & 0.063 \\
\hline \multicolumn{7}{|l|}{ Mother's education } \\
\hline No education & 1.17 & $(0.96-1.43)$ & 0.138 & & & \\
\hline Primary & 1.20 & $(0.95-1.51)$ & 0.168 & & & \\
\hline Secondary or higher & 1.00 & & & & & \\
\hline \multicolumn{7}{|l|}{ Mother's literacy level } \\
\hline Cannot read at all & 1.23 & $(1.03-1.46)$ & 0.020 & & & \\
\hline Able to read & 1.00 & & & & & \\
\hline \multicolumn{7}{|c|}{ Mother's desire for pregnancy } \\
\hline Wanted then & 1.00 & & & & & \\
\hline Wanted later & 1.07 & $(0.78-1.48)$ & 0.670 & & & \\
\hline Wanted no more & 1.17 & $(0.78-1.76)$ & 0.442 & & & \\
\hline
\end{tabular}



mortality (Continued)

Individual related factors

Mother's body mass index

$\mathrm{BMI}>18.5$

1.00

$\mathrm{BMI} \geq 18.5$

1.08

(0.84-1.38)

0.566

Missing

Mother's working status

Not working

1.00

Working

0.97

(0.83-1.15)

0.749

Missing

\section{Sex of child}

Female

Male

Mother's perceived baby size

Small or very small

Average or larger

1.00

1.29

(1.11-1.51)

0.001

1.00

1.30

(1.12-1.53)

0.001

$(1.82-2.58)$

$<0.001$

2.10

$(1.77-2.50)$

$<0.001$

Birth order and birth interval

First child

(1.38-2.25)

$<0.001$

1.32

(1.01-1.72)

0.040

2 or 3 child, interval $>2$

1.00

2 or 3 child, interval $\leq 2$

4 or more child, interval $>2$

1.78

(1.34-2.38)

$<0.001$

1.00

1.28

(1.01-1.62)

0.039

1.75

$(1.31-2.34)$

$<0.001$

2.10

(1.64-2.70)

$<0.001$

$(1.05-1.78)$

0.022

4 or more child, interval $\leq 2$

Mode of delivery

Non-caesarean

Caesarean section"'

1.00

2.33

(1.54-3.51)

$<0.001$

$(1.68-2.84)$

$<0.001$

Delivery assistance

Health professional

non-Health professional

1.00

1.99

(0.84-1.17)

0.924

Birth place of child

Health facility

1.00

Home

1.00

(0.84-1.17)

0.955

"'Caesarean section is a combination of both elective and emergency caesarean. *Interval for 30-39 years and 40-49 years were merged.

${ }^{\wedge} 2,465$ missing information were not included in the analysis.

$\mathrm{HR}$, hazard ratio; P-values based on Cox regression.

We found that the NMR for singleton live-born infants between 2003 and 2008 was 36.7 (95\% CI: 34.4-39.0). However, a preliminary report from the 2013 NDHS indicated that the NMR slightly fell by approximately $8 \%$ from 40 deaths per 1000 live births in 2008 to 37 in 2013 [23]. Despite this decline, Nigeria still has a long way to go in achieving the Millennium Development Goal 4 target for the under- 5 years of age mortality rate.

Our study showed that male neonates had a significantly higher risk of dying during the neonatal period compared with female neonates. This finding is consistent with a cross-sectional study conducted in Indonesia in 2008, which indicated that male neonates were more likely to die than female neonates [19]. Additionally, a cross-sectional study performed in Bangladesh in 2009 reported a lower relative risk for female neonates compared with male neonates [24]. An increased risk of dying in the first month of life among male neonates may be attributed to high vulnerability to infectious disease [25]. Another possible reason for the low rate of neonatal deaths among girls may be because of the development of early fetal lung maturity in the first week of life [26], resulting in a lower incidence of respiratory diseases in female neonates compared with male neonates. 
Globally, it is estimated that approximately $23 \%$ of newborn deaths are attributed to respiratory problems [27].

In our study, mothers who perceived the size of their newborns to be small or very small had a 2.26 times greater risk of dying in the first month of life than those mothers who perceived their neonates to be of average or larger size. Similarly, findings from a cross-sectional study conducted in five Asian countries (India, Indonesia, Nepal, Bangladesh, and the Philippines) in 2008 also showed that smaller than average neonates had an increased risk of neonatal deaths than average or larger sized neonates in four of the five countries with data on perceived newborn size [28]. Even though our finding on perceived size of newborns were significant, we need to exercise caution in interpreting this result because the rationale mothers used in estimating the size of their neonates is unclear. However, this measure is not an unreasonable proxy for birth weight because a previous study showed a correlation between perception of birth weight and actual birth weight [21].

Our study showed that neonates delivered by caesarean section had a higher relative risk of neonatal mortality compared with vaginal deliveries. This result contradicts previous reports, which indicated a statistically insignificant relationship between the mode of delivery and neonatal mortality [29]. A similar study conducted in Swaziland reported a higher risk of death for neonates delivered by caesarean section than vaginal delivery, but this was not significant [30]. The significantly high risk of caesarean section observed in our study may be attributed to negative perceptions, such as misconception, fear, and aversion to caesarean section among mothers in Nigeria [31,32]. This could explain why pregnant mothers are presented to health facilities after experiencing labor at home or elsewhere, with life-threatening complications for emergency caesarean section [33]. This is also supported by a recent study on caesarean section and perinatal mortality in South Western, Nigeria, which found that nearly $84 \%$ of early neonatal deaths occurred in pregnant mothers who delivered their newborns by emergency caesarean section [34].

The current study observed that neonates born to mothers aged younger than 20 years had a significantly higher risk of mortality than those born to mothers aged 20-29 years, $30-39$ years, and $40-49$ years. This finding is similar to that reported in previous studies $[35,36]$. However, our analysis is not consistent with crosssectional studies conducted in Swaziland and Tanzania, which found no significant relationship between maternal age and neonatal mortality [30,37]. This significantly higher rate of death in Nigeria could be related to inadequate use of maternal health services, physical immaturity, poor nutritional status, inexperience regarding child rearing among younger mothers, and poor maternal health outcomes, such as pregnancy complications. These factors are more common in younger mothers, and are all possible factors that could lead to higher adverse effects of neonatal and child health outcome in young motherhood [35].

We found that children of birth order ( 2 through 4 or higher) born with a shorter birth interval ( $\leq 2$ years) were at higher risk of dying than those with a longer birth interval ( $>2$ years). This finding is similar to a crosssectional study carried out in India, which showed that neonates of fourth or higher birth order with a shorter birth interval of $<2$ years have an increased risk of death compared with those of second and third birth order with a longer birth interval of $>2$ years [38]. Maternal depletion syndrome could be attributed to this finding. Short-interval births could have adverse effects on the mother's biological well-being and there could be economic resource competition between infants, especially in poor households, as well as inadequate care given to infants compared with high-ranked infants [39].

The current study showed that neonates born to mothers residing in rural areas had a higher risk of neonatal mortality compared with those living in urban areas. This finding is consistent with previous studies [40,41], which attributed this finding to limited access to health facilities and maternal healthcare services, such as delivery assisted by a healthcare professional, and prenatal and postnatal care. This disproportionally hinders rural dwellers from receiving adequate healthcare services, resulting in a high probability of neonatal death. In Nigeria, as in many developing countries, the majority of well-equipped hospitals and health centers are typically located in urban areas. However, neonatal jaundice and sepsis, as well as gestational age, which were previously found to be significantly associated with neonatal morality in most hospitalbased studies [42,43], were not examined in our study. These variables could potentially be determinants of neonatal mortality in Nigeria.

The strengths and weaknesses of this study need to be considered when drawing specific inferences. This study was a nationally representative survey, with a stratified two-stage cluster sampling design, which achieved a 98.3\% response rate. Additionally, recall errors arising from dates of birth and death given by women interviewed in the survey were minimized by restricting our analyses to births within the 5-year period preceding the survey. Third, the proportion of missing data was relatively small, such that it may not have influenced findings in our study. Despite these strengths, a number of weaknesses were also present in the study and they are as follows. (1) Only surviving women were interviewed, which may have led to under-reporting of the number of newborn deaths because of the association of neonatal death with maternal death [22]. (2) Gestational age, which 
may be an important risk factor for neonatal mortality, was not examined in this study. (3) Other factors previously found to be associated with neonatal mortality, such as antenatal care, postnatal care, and birth weight at birth, were lacking in information in the 2008 NDHS. (4) The Demographic and Health Surveys are the largest source of national data, but they are expensive and time consuming, and in Nigeria, this survey is usually conducted once in every 5 years. (5) Causal effects could not be measured because the study was based on a retrospective crosssectional study.

A community-based interventional study on reducing neonatal death in Nigeria should be performed to focus on using verbal autopsy and birth weight. To reduce the recall period of using these instruments, a verbal autopsy should be undertaken before the culturally prescribed mourning period [44]. In addition, traditional birth attendants should be provided training or refresher training on delivery, how to recognise signs of pregnancy complications, and how to measure the newborn's weight at birth because approximately $62 \%$ of mothers in Nigeria deliver their newborns at home [7].

\section{Conclusions}

Our analysis of factors associated with neonatal mortality in Nigeria revealed that living in rural areas, child bearing at a younger age, birth order and birth interval, sex of the newborn (being male), caesarean delivery, and mothers who perceive their newborns as smaller than average at birth significantly increased the risk of neonatal death. Our findings indicate the need to implement community based newborn care interventions particularly, educating community health workers and traditional birth attendants about safe delivery practice, the benefits of Kangaroo mother care method on low birth weight newborns, child spacing and promote delay of first pregnancy will contribute to the improvement of neonatal mortality statistics in Nigeria.

\section{Competing interests}

The authors declare that they have no competing interests.

\section{Authors' contributions}

OKE and KEA were involved in the conception and design of this study. OKE carried out the analysis and drafted the manuscript. KEA, MJD, JH, and ANP gave advice on interpretation and revised and edited the manuscript. All authors read and approved the final manuscript.

\section{Acknowledgements}

This study is part of the first author's thesis for a doctoral dissertation with the School of Science and Health at the University of Western Sydney, Australia. We are grateful to Measure DHS, ORC Macro, Calverton, MD, USA for providing the 2008 NDHS data for this analysis.

\section{Author details}

${ }^{1}$ School of Science and Health, University of Western Sydney, Locked Bag 1797, Penrith, New South Wales (NSW) 2571, Australia. ${ }^{2}$ Sydney School of Public Health, Edward Ford Building (A27), University of Sydney, Sydney,
NSW 2006, Australia. ${ }^{3}$ School of Medicine and Public Health, Faculty of Health, University of Newcastle, Callaghan, NSW 2308, Australia.

Received: 9 July 2013 Accepted: 19 May 2014

Published: 29 May 2014

\section{References}

1. UNICEF: The state of the world's children 2008. Child Surviv. http://www. unicef.org/sowc08/docs/sowc08.pdf.

2. Rajaratnam JK, Marcus JR, Flaxman AD: Neonatal, postneonatal, childhood, and under-5 mortality for 187 countries,1970-2010: a systematic analysis of progress towards millennium development goal 4. Lancet 2010, 375:1988-2008.

3. Lawn JE, Cousens S, Zupan J: Neonatal survival 1: 4 million neonatal deaths: when? where? where? why? neonatal survival series paper 1 . Lancet 2005, 365:891-900.

4. Lawn JE, Lee AC, Kinney M: Two million intrapartum-related stillbirths and neonatal deaths: where, why, and what can be done? Int J Gynaecol Obstet 2009, 107:S5-S19.

5. Inter-agency Group for Child Mortality Estimation (IGME): Levels and Trends in child mortality. 2012. http://www.who.int/maternal_child_adolescent/ documents/levels_trends_child_mortality_2012.pdf.

6. Lawn JE, Kerber K, Enweronu-Laryea C, Cousens S: 3.6 millions neonatal deaths- what is progressing and what is not. J Semperi 2010, 34:371-386.

7. National Population Commission, Federal Republic of Nigeria: Final Report on Nigeria Demographic and Health Survey. Calverton, Maryland, USA: ORC Macro; 2008:118-133.

8. Adetola $\mathrm{AO}$, Tongo $\mathrm{OO}$, Orimadegun $\mathrm{AE}$, Osinusi $\mathrm{K}$ : Neonatal mortality in an urban population in Ibadan, Nigeria. Pediatr Neonatol 2011, 52(5):243-50.

9. Onayade AA, Sule SS, Elusiyan JB: Determinants of neonatal mortality at Wesley guild hospital, llesa, Nigeria. Niger J Med 2006, 15(3):271-276.

10. Fawole AO, Shah A, Tongo O, Dara K, El-Ladan AM, Umezulike AC, Alu FE: Determinants of perinatal mortality in Nigeria. Int J Gynaecol Obstet 2011, 114(1):37-42.

11. Ibe OE, Austin T, Sullivan $K$, Fabanwo O, Disu E, Costello AM: A comparison of kangaroo mother care and conventional incubator care for thermal regulation of infants $<2000 \mathrm{~g}$ in Nigeria using continuous ambulatory temperature monitoring. Ann Trop Paediatr 2004, 24(3):245-251.

12. National Population Commission, Federal Republic of Nigeria: Final Report on Nigeria Demographic and Health Survey. Calverton, Maryland, USA: ORC Macro; 1999:99-109.

13. National Population Commission, Federal Republic of Nigeria: Final Report on Nigeria Demographic and Health Survey. Calverton, Maryland, USA: ORC Macro; 2003:108-121.

14. Gorthmaker SL: Poverty and infant mortality in the United States. Am Sociol Rev 1979, 44(2):280-297.

15. Moseley HW, Chen LC: An analytical framework for the study of child survival in developing countries. Popul Dev Rev 1984, 10(Supplement):25-45.

16. Sharma RK: Causal pathways to infant mortality: linking social variables to Infant mortality through intermediate variables. J Health Soc Pol 1998, 9(3):15-28.

17. Meegama SA: Socio-economic determinants of infant and child mortality in Sri Lanka: an analysis of post-war experience. World Ferti Surv Sci Rep 1980, 8 .

18. Sastry N: What explains rural-urban differentials in child mortality in Brazil? Soc Sci Med 1997, 44:989-1002.

19. Titaley CR, Dibley MJ, Agho K, Roberts $C L$, Hall J: Determinants of neonatal mortality in Indonesia. BMC Public Health 2008, 8:232.

20. Filmer D, Pritchett LH: Estimating wealth effects without expenditure data or tears: an application to educational enrolments in states of India. Demography 2001, 38(1):115-132.

21. Titaley CR, Dibley MJ, Roberts CL, Hall J, Agho K: Iron and folic acid supplements and reduced early neonatal deaths in Indonesia. Bull World Health Organ 2010, 88:500-508

22. Rutstein SO, Rojas G: Guide to Demographic and Health Survey (DHS). Calverton, Maryland: ORC Macro; 2006:93-102.

23. National Population Commission, Federal Republic of Nigeria: Preliminary Report on Nigeria Demographic and Health Survey. 2013. http://www. measuredhs.com/what-we-do/survey/survey-display-438.cfm. 
24. Mondal NI, Hossain K, Ali K: Factors influencing infant and child mortality: a case study of Rajshashi district, Bangladesh. J Hum Ecol 2009, 26(1):31-39.

25. Alonso V, Fuster V, Luna F: Causes of neonatal mortality in Spain (1975-98): influence of sex, rural-urban residence and age at death. J Biosoc Sci 2006, 38(4):537-551.

26. Khoury MJ, Marks JS, McCarthy BJ, Zaro SM: Factors affecting the sex differential neonatal mortality: the role of respiratory distress syndrome. Am J Obstet Gynecol 1985, 151(6):777-782.

27. World Health Organisation: The global burden of disease: 2004 update. 2008, http://www.who.int/topics/global_burden_of_disease/en/.

28. Fort AL, Kothari MT, Abderrahim N: Association between maternal, birth, and newborn characteristics and neonatal mortality in five Asian countries. DHS Work Papers 2008, No 55.

29. Seedhom AM, Kamal NN: Some determinants of neonatal mortality in a ruralarea, EL-Minia governorate, Egypt, 2008. Egypt I Community Med 2010, 28(2).

30. Zwane $E$, Masango S: Factors influencing neonatal mortality: an analysis using the Swaziland demographic and health survey, 2007. J Publ Health Af 2012, 3:e18.

31. Orji EO, Ogunniyi SO, Onwudiegwu U: Beliefs and perceptions of pregnant women at llesa about caesarean section. Trop J Obstet Gynaecol 2003, 20(2):141-143.

32. Okonufua F: Optimizing caesarean section rates in West Africa. Lancet 2001, 58:1289

33. Sunday-Adeoye I, Kalu CA: Pregnant Nigeria women's view of caesarean section. Niger J Clin Pract 2011, 14:276-279.

34. Ezechi OC, Loto OM, Ndububa VI, Okogbo FO, Ezeobi PM, Nwokoro CA: Caesarean section and perinatal mortality in South Western Nigeria. NJOG 2009, 4(1):46-48.

35. Mostafa Kamal SM: What Is the association between maternal age and neonatal mortality? An analysis of the 2007 bangladesh demographic and health survey. Asia Pac J Public Health 2011, XX(X):1-12.

36. Conde-Agudelo A, Belizan JM, Lammers C: Maternal-perinatal morbidity and mortality associated with adolescent pregnancy in latin America: cross-sectional study. Am J Obstet Gynecol 2005, 192:342-349.

37. Ajaari J, Masanja H, Weiner R, Abokyi SA, Owusu-Agyei S: Impact of place ofdelivery on neonatal mortality in rural tanzania. Int J MCH Aids 2012, I(l):49-59.

38. Arokiasamy P, Gautam A: Neonatal mortality in the empowered action group States of India: trends and determinants. J Biosoc Sci 2008, 40(2):183-201.

39. Rutstein SO: Effects of preceding birth intervals on neonatal, infant and under-five years mortality and nutritional status in developing countries: evidence from the demographic and health surveys. Int I Gynaecol Obstet 2005, 89(Suppl 1):S7-S24.

40. Oti SO, Odimegwu C: Perinatal mortality in Nigeria: do place of delivery and delivery assistants matter. Open Demography J 2011, 4:1-10.

41. Golding J, Greenwood R, McCaw-Binns A, Thomas P: Associations between social and environmental factors and perinatal mortality in Jamaica. Paediatr Perinat Epidemiol 1994, 8(1):17-39.

42. Omoigberale Al, Sadoh WE, Nwaneri DU: A 4 year review of neonatal outcome at the University of Benin teaching hospital, Benin city, Nigeria. Niger J Clin Pract 2010, 13(3):321-325.

43. Njokanma OF, Olanrewaju DM: A study of neonatal deaths at the Ogun state university teaching hospital, Sagamu, Nigeria. J Trop Med Hyg 1995, 98(3):155-160.

44. World Health Organisation: The WHO verbal autopsy standard 2012. http://www.who.int/healthinfo/statistics/WHO_VA_2012_RC1_Instrument.pdf.

doi:10.1186/1471-2458-14-521

Cite this article as: Ezeh et al:: Determinants of neonatal mortality in Nigeria: evidence from the 2008 demographic and health survey. BMC Public Health 2014 14:521.

\section{Submit your next manuscript to BioMed Central and take full advantage of:}

- Convenient online submission

- Thorough peer review

- No space constraints or color figure charges

- Immediate publication on acceptance

- Inclusion in PubMed, CAS, Scopus and Google Scholar

- Research which is freely available for redistribution

Submit your manuscript at www.biomedcentral.com/submit
C Biomed Central 